their velocity will have increased to 450 miles per second, and that the pressures in the center as they strike and flatten would be of the order of $1,000,000,000$ tons per square inch. $\mathrm{He}$ also estimates that the heat equivalent of the energy would be sufficient to vaporise the whole mass 100,000 times over. This immense pressure would be maintained for many minutes, perhaps for half an hour.

Let us consider what is the greatest pressure that can be produced artificially. If the German gun which bombarded Paris were loade with a solid steel projectile somewhat shorter and lighter than the one actually used, a muzzle velocity of about 6000 foot-seconds might be reached (many years ago Sir Andrew Noble had reached 5000 foot-seconds); and if it was fire into a tapered hole, as I have described, in a large block of steel, this would give the greatest instantaneous pressure that can be produce artificially so far as we at present know, viz. about 7000 tons per square inch; it is only about $1 / 150,000$ th part of that possible by the collision of the largest stars.

As to the temperature and conditions of matter under these intense pressures, extrapolation from known data is valueless. We have no knowledge of the coefficients of compressibility of matter under these conditions or of its specific heat. What may be the effect on the atom? And will elements under such conditions be transforme into others of higher atomic weight?

Some of us may recall that in 1888 a lecturer, after describ- ing in this room the experiment in which oxygen at atmospheric pressure was passe in close contact with a platinum surface heate by the oxyhydrogen burner to nearly its melting point, and then immediately cooled by contact in water, said :

"In this experiment ozone is formed by the action of a high temperature, owing to the dissociation of the oxygen molecules and their partial recombination into the more complex molecules of ozone. We may conceive it not improbable that some of the elementary bodies might be iormed somewhat like the ozone in the above experiment, but at very high temperatures, by the collocation of certain dissociated constituents and with the simultaneous absorption of heat."

It seems indeed probable that the centers of the great stars and stars in collision may be the laboratories where the elements as they gradually degenerate are being continually regenerate into others of higher intrinsic energy, and where endothermic processes, such as the recombination of lead and helium into radium, may be taking place, absorbing in this process an energy 2,500,000 times that developed by the explosion of an equal weight of T.N.T.

The transformation of only a minute fraction of the mass of two colliding stars would therefore be amply sufficient to absorb the whole energy of their collision.

Emerson said many years ago, "None but the elements can themselves destroy."

\title{
Manufacture of Carbon Black from Natural Gas ${ }^{*}$
} Utilization of Low Pressure Gas in Fields Abandoned by Gas Companies

\section{By Roy $\mathbf{0}$. Neal}

\section{$\mathrm{T}$} HERE seems to be some confusion between the terms carbon black and lamp black, although in American trade lampblack is generally understood to be a soot formed by the smudge process. In this process oil, coal tar, resin or some solid, or liquid carbonaceous substance is burned in an insufficient quantity of air, while on the other hand carbon black is a product resulting from the incomplete combustion of gas and is deposite by actual contact of fiame upon a metallic surface.

The various carbons, such as gas retort coke, oil retort coke, graphite, carbon black, lampblack, vine black, wood pulp black, willow charcoal, and blacks made from refuse material such as leather have different characteristics as to flocculence, strength of color, and physical structure. These blacks are made by one of the following methods:

(1) Formation by direct contact of a flame upon a depositing surface.

(2) Production by combustion of an oil, tar, etc., in an inadequate supply of air; the soot is allowed to slowly settle out on the floors and the walls of the collecting chambers.

(3) Carbonization of solids and subsequent reduction to a state of small subdivision.

(4) Production by heating carbonaceous vapors or gases to a decomposition temperature by external heating, with or without air in the forming chamber.

Each black has its specific use that in most cases cannot be met by another black. It is often difficult to apply the usual tests to determine which to use on account of the modification in properties upon combination with other substances. In what follows the black resulting from the incomplete combustion of natural gas is taken up and is designated as carbon black although often in the trade it is referred to as gas black, natural gas black, ebony black, jet black, hydrocarbon black, satin gloss black, and silicate of carbon.

The estimated production of carbon black for the year 1918 was 43,500,000 pounds, of which $30,000,000$ pounds was manufacture in West Vinginia, and only 1,500,000 pounds was

*From Monthly Reports of Investigations of the U. S. Bureau of Mines. manufacture in Oklahoma. This year will probably show a decrease in production of West Virginia and a material increase for Louisiana, where a large number of plants have recently been built. In the Monroe, Louisiana, gas field, which is probably the largest in the world today, the gas can be obtained for two cents per thousand cubic feet, whereas in West Virginia the carbon-black operators are paying about three cents. The industry is necessarily a migratory one and usually finds its home in an isolated district where there is an abundant supply of gas with insufficient marketing facilities. Judging from plant production, the average yield of carbon black in pounds per thousand cubic feet is probably 0.85 for Louisiana, 1.10 for West Virginia, 1.1 for Oklahoma and 1.4 for Wyoming.

The estimate distribution of carbon black per annum is:

Lbs.

Rubber industry . . . . . . . . . . 20,000,000

Printers' ink . . . . .

Export $\ldots \ldots \ldots \ldots \ldots \ldots \ldots \ldots \ldots \ldots, 8,000,000$

Stove polish $\ldots \ldots \ldots \ldots \ldots \ldots \ldots \ldots, 4,000,000$

Phonograph records ............. 500,000

Other uses $\ldots \ldots \ldots \ldots \ldots \ldots \ldots \ldots \ldots \ldots \ldots \ldots, 1,000,000$

Under other uses are paint, carbon paper, type ribbon, tarpaulins, carriage cloth, black leather, paper, bookbinders' board, shoe polish, electric composition insulators, celluloid, buttons, etc. At present the export trade is small, pending the establishment of a stable basis of credit with Germany and Austria, but considerable quantities are shipped to England, France, Japan and China. During pre-war times one-third of the annual production was exported.

The first carbon black made in 1872 sold for $\$ 2.50$ per pound; this price rapidly decreased until it reached the low mark of five cents per pound in 1912. In 1915 support was given the carbon black market when the beneficial results of the use of carbon black in rubber tire-making was discovered. The market price of carbon black has increased and has not since fallen below eight cents, during the past two years it has sold for as much as sixteen cents. The grade 
of black above mentioned is that used by the rubber and newspaper ink trade, and constitutes the bulk of the production, although there are some grades, such as the Peerless black that bring as much as thirty-five cents at the present time. The latter is use in limited quantities in making embossing and high grade lithographic ink.

When planning the construction of a carbon-black plant, information on the following points should be obtained: distance from railroa or navigable stream, depth of wells, thickness of gas-bearing strata, gas pressure, gasoline content and knowledge as to whether gas is casing-head or dry, amount of proven territory, history of field, drilling practice, location of field in regard to large centers for domestic and industrial distribution of gas, distance from large trunk pipelines for transportation of gas, open flow capacity of gas wells on prospective leases, and a test on the richness of gas for the approximate quantity of carbon black that one expects to procure per thousand cubic feet.

The carbon black value is determine either by chemical analysis of the gas or by a test apparatus in which a known quantity of gas is burned and the carbon black that is deposite upon a plate is collected and weighed. By chemical analysis the yield of carbon black is computed from the percentage of ethane, heating value, and the carbon content. Louisiana gas contains 3.44 per cent ethane, has a heating value of 962, a carbon content of $33.8 \mathrm{lb}$. per thousand and only 0.8 of a pound is obtained per thousand cubic feet; whereas Wyoming gas which contains 43.1 per cent ethane, has a heating value of 1176 , and a carbon content of $44.3 \mathrm{lb}$. per thousand, the yield is 1.4 pounds. There are four commercial processes of making carbon black classified according to the quantity of carbon black produced. The order is as folløws: channel, small disk, large plate and roller processes.

\section{CHANNEL PROCESS.}

Briefly the channel process is as follows: The gas from the wells is reduced in pressure by suitable regulators, and then goes through gasometers that regulate the flow by a butterfly valve. The gas then passes to the burners in the condensing buildings, special precautions being taken in the pipe-line design to obtain equal distribution of gas in all the buildings. The condensing buildings are sheet-iron buildings about 100 feet long and from 10 to 8 feet in width, arranged in rows along both sides of an alley. Through the center of the alley, and at right angles to the condenser units, is the main uriving shaft, which operates the machinery within the units.

On the interior of the buildings are tables of channels, beams having eight 8 -inch channels that travel on trucks supported by a trestle 6 feet high and 66 inches wide. The channels have a reciprocating motion of about 55 inches. The gas is burne through ordinary lava tips with an even, luminous, and smoky flame, the draft being regulated by a slide door or slits at the base of the buildings or by the chimneys. There are about 1600 tips per building. The carbon black is deposite upon the underside of the channels. Underneath the channels and spaced every four feet are sheet-iron hoppers to catch the carbon removed by scrapers set in the hoppers. Connected to the hoppers is a spiral conveyor that carries the black to the bolting room. The bolters are galvanize sheet-iron drums having a layer of 45 to 60-mesh iron screen held by heavy wire as reinforcement over which fiber brushes rotate; the purpose of the device is to remove grit, scale and like material. From the bolters, the product is elevated by an endless chain to a storage bin, whence it is packed in $121 / 2$-pound sacks.

The plants are usually built in 60-barrel units (50 pounds per barrel) and have 18 buildings. The channels and other moving mechanism weigh about 200 tons. This is actuated by a 20 to 25-h.p. internal combustion gas or expansion engine. The operating cost is about 2 cents per pound (exclusive of cost of gas) and the construction cost at present is about $\$ 2,500$ per barrel per day.

\section{ROTATING DISK.}

The disks are made of cast iron, 36 to 40 in. diameter, having a 6-in. face and, together with the gear and pinion, resemble flat umbrellas. The hopper and scraper radiate from the shaft and, like the burners, are stationary. The burners are in the form of rings with lava tips inserted about the upper part of the ring. The disks are set in rows of 21 each, with four rows to the condensing building, and a separate driving shaft for each row of disks. The pinions are of special design having teeth about 4 inches wide that mesh with 2 -inch teeth on the gear. This arrangement is to take care of expansion and contraction. Other details of the plant are the same as in the channel system.

\section{PLATE PROCESS.}

The plates upon which the carbon black is deposite are 24 feet in diameter, and made up of 48 segments, which are supporte by a central mast and cables. The plates are stationary while the burners and scraper rotate, making one revolution every eight minutes. There are 1265 tips to each plate. The plates are surrounded by a circular building 26 feet in diameter, made of corrugated sheet iron. The conveyor system, bolting, and packing process are the same as in the preceding systems. One company has as many as 113 rings and a daily production of 10,000 pounds.

\section{ROLLER METHOD.}

In the roller process the gas is burned through lava tips, having a round perforation instea of fish tail. The rollers are 8 inches in diameter and three feet in length, making one revolution in thirty minutes. The scrapers are set on top of rollers and scrape continuously. From 6 to 9 rollers are inclosed in one hood. In one plant visite there were 1150 rollers and 40,000 tips, with a prodiction of only 300 pounds per day. The yield per thousand cubic feet is very small but the product commands a high price, about 35 cents at present. It is used in making embossing and high grade lithographic inks.

\section{THERMAL DECOMPOSITION.}

Thermal decomposition, or the subjection of oil vapors or gas to cracking temperatures with or without the presence of air, is not a commercial success at present inasmuch as the resulting carbon is heavy, contains tarry matter and is off color. A company in western Oklahoma erecte a cracking chamber for making black from natural gas and found that the product was salable. A jobber said that it was not good for any purpose except perhaps to blacken the face of a minstrel. The process, however, furnishes a promising field for future research. Possibly by using a properly designed cracking chamber, sudden cooling, using some catalyser, employing pressure or the admission of a suitable quantity of air, the process will become a commercial success and capable of producing a black having the same properties possessed by the ordinary carbon black on the market today.

\section{ECONOMICS OF CARBON BLACK INDUSTRY.}

It is generally conceded that the most useful purpose that natural gas can be applied to is for domestic consumption, but whether gas is of greater economic value for the manufacture of carbon black than for other industrial uses is a question that must be decided on the basis of conditions existing in each locality in which a large supply of natural gas is available.

The utilization of low-pressure gas, discharge gas from natural gas gasoline plants, gas in isolated districts, and fields which have been abandoned by other gas companies on account of low pressure, for the manufacture of carbon black, is in reality often a conservation measure and is preferable to the common practice of letting the gas go to waste.

The utilization of natural gas for domestic consumption is possibly the most beneficial use that can be made of gas, and it is not recommended that gas be use for the manufacture of carbon black where there is an available market for the gas for domestic purposes. 